\title{
Comparison of two methods for obtaining spermatozoa from the cauda epididymis of Iberian red deer
}

\begin{abstract}
We have compared two methods for salvaging epididymal sperm from post-mortem samples from Iberian red deer. Of each pair of testicles ( 29 samples), one cauda epididymis was processed by means of cuts (sperm was immediately diluted with extender) and the other was detached from the corpus and flushed from the vas deferens with $1 \mathrm{~mL}$ of extender. Sperm was processed for cryopreservation, and analyzed just after recovery, pre-freezing and post-thawing. Total spermatozoa recovered, contamination (concentration of epididymal cells and red blood cells (RBCs)) and quality (motility by CASA, and acrosomal status, viability and mitochondrial status by flow cytometry) were used to compare both methods. The number of recovered spermatozoa was similar for both methods. Contamination was higher for the cuts method, but when considering the final dilution before freezing, only RBCs concentration was significantly higher. Motility was similar just after extraction, but higher for both pre-frozen and post-thawed flushed sperm. Pre-freezing acrosomal status $(P<0.05)$ and viability $(P<0.1)$ were better for flushing; however post-thawing results were similar for the two methods. A clustering analysis using CASA data showed that the subpopulation pattern of motile sperm was different depending on the method, being better for flushing. With regard to yield, lower contamination (especially RBCs) and, in general, better quality results, flushing seems to be a more recommendable method for post-mortem sperm recovery. The cuts method may be more
\end{abstract}

* Corresponding author. Tel.: +34 987291 320; fax: +34 987291320 .

E-mail address: dsalar@unileon.es (L.A. Rodríguez). 
practical on certain occasions, but care must be taken in order to achieve rapid extension of the sample and to avoid contamination in order to improve sample condition.

(C) 2005 Published by Elsevier Inc.

Keywords: Red deer; Post-mortem recovery; Contamination; Epididymal sperm; Method comparison

\section{Introduction}

Germplasm banks have arisen as one of the most interesting means of conserving biodiversity, endangered due to habitat destruction and human activity [1]. However, gamete collection has still to overcome many issues related to the characteristics of the species involved, thus the techniques available in domestic species are frequently inappropriated. Considering the nature of wild species and the advisability of minimizing disturbance, the collection of epididymal sperm from harvested or accidentally dead males appears as a suitable and convenient option, since it is known that spermatozoa from the cauda epididymis have an adequate degree of maturity and fertility [2,3].

One of the first steps in a protocol for cryopreserving epididymal sperm is salvaging it from the cauda epididymis. Many methods of recovery have been described and vary depending on authors and species. In the case of small animals, due to the size of the epididymis, the preferred method (flotation method) consists of mincing or slicing the cauda epididymis in a buffered medium and allowing it to rest for some minutes. In this manner, the spermatozoa will swim into the medium and are recovered by filtration of the carefully collected medium [4-7]. This technique is also being used with samples from large animals $[8,9]$.

A similar technique is to make numerous cuts on the cauda with a blade, gently squeeze the cauda and collect the spermatic fluid emerging from the cut tubules [8-10,11]. Another possibility is to use a needle to puncture the tubules [12]. Furthermore, Kishikawa et al. [13] used forceps to squeeze the cauda epididymis of mice in order to recover the spermatozoa.

Another widely used method consists of the retrograde flushing of the cauda epididymis by applying pressure from the vas deferens until the contents of the cauda emerge from a cut made near the junction with the corpus. The pressure is generated from a syringe, which usually also injects some media, thus the sample is already slightly diluted when recovered. This technique has been extensively used in many species, both domestic [14-16] and wild [17-20]. Other authors use no medium, just air [21-23].

However, there is a lack of information on these techniques. It is necessary to evaluate their impact on sperm characteristics and their suitability for inclusion in germplasm banking protocols need to be evaluated, determining which techniques are more adequate for each situation. To our knowledge, only Cary et al. [24] have carried out such studies, comparing flushing and flotation methods.

The purpose of this work was the comparison of two methods for obtaining sperm samples from the cauda epididymis of red deer. Our research group has been working on epididymal sperm for many years, mainly from wild ruminants, and with special interest in Iberian red deer [25-30]. Most of our work has been aimed at adapting and improving protocols for setting up germplasm banks based on the storage of doses prepared from 
epididymal sperm collected post-mortem. However, as there is very little information on salvaging methods, we have carried out a study to compare two methods of sperm recovery from the cauda epididymis of red deer by means of cuts or by flushing. The aim of this study was to establish which was the best method for salvaging epididymal samples, by comparing the yield, sample contamination (by epididymal tissue or blood) and sample quality obtained with each one, with a view to using this kind of sample for germplasm banking in the future.

\section{Materials and methods}

All reagents were obtained from Sigma (Madrid, Spain). Media were prepared in our laboratory, not purchased as such.

\subsection{Genitalia collection}

Genitalia were collected from 29 Iberian red deer (Cervus elaphus hispanicus), in the game reserves of Ancares, Mampodre and Picos de Europa (Cantabrian mountains in Leon, Spain), and in several private game reserves in Caceres (Spain). All the animals were adults and lived in a free-ranging regime. Harvesting was carried out during the breeding season (autumn). Scrotum, including testicles and epididymes, was removed from the carcass and refrigerated down to $5{ }^{\circ} \mathrm{C}$ as soon as possible. Date and time of death, collection and refrigeration were noted and attached to the corresponding sample. Refrigerated genitalia were sent to our laboratory at the Veterinary Clinic Hospital of the University of Leon (Spain).

Harvest plans followed the Spanish Harvest Regulation, Law 4/96 of Castilla y Leon and Law 19/01 of Extremadura, which conforms to European Union Regulations. The species and number of individuals that can be hunted, as well as the exact times of the year when hunting can take place, are reviewed each year by the Annual Hunting Regulation of the respective regions. Animal handling was performed in accordance with the Spanish Animal Protection Regulation, RD223/1998, which conforms to European Union Regulation 86/609 and adheres to guidelines established in the guide for care and use of laboratory animals as adopted and promulgated by the American Society of Andrology.

\subsection{Sperm recovery}

The processing of the samples was carried out in a walk-in fridge $\left(5^{\circ} \mathrm{C}\right)$. Genitalia were dissected, isolating the epididymides and vasa deferentia. For each sample, it was randomly decided which epididymis was to be processed by cuts and which by flushing. Only samples taken $24 \mathrm{~h}$ post-mortem were used for the quality assessments (see below), since we considered that longer post-mortem times might have a negative influence on their quality [25].

\subsubsection{Recovery by cuts}

One of the epididymis was thoroughly cleaned, and the superficial blood vessels of the cauda were punctured, so that most of the blood could be wiped off. Then, we extracted the 
sperm from the cauda by means of cuts performed with a scalpel, removing the white fluid coming out of the cut tubules with the aid of the blade. Immediately after the extraction, the sample was diluted 1:1 with extender (Tes-Tris-Fructose, $10 \%$ egg yolk and $4 \%$ glycerol [10]).

\subsubsection{Recovery by flushing}

The other epididymis was cleaned, and the cauda + vas deferens were isolated from the rest of the epididymis by making a cut near the junction of the corpus and the proximal cauda. We then carried out retrograde washing of the vas deferens and cauda epididymis. We used a syringe loaded with $1 \mathrm{~mL}$ of the same extender used in the cutting method, and cannulated the vas deferens using a blunted $21 \mathrm{G}$ needle. The vas deferens and cauda were perfused with the extender, injecting air afterwards, until all the contents were flushed out of the cauda epididymis. The sample was collected in a plastic tube. It was sometimes necessary to make extra cuts in the cauda epididymis in order to allow the fluid to emerge. The extra cuts did not alter the recovered sample as they were made at the same time as the first ones to remove slices of tissue that might hamper sample extraction.

\subsection{Determination of the number of recovered spermatozoa and contamination by blood or epididymal cells}

Sperm concentration was estimated using a Burker chamber and a phase-contrast microscope $(400 \times)$. Then, the total number of sperm recovered with each method was estimated by means of multiplying the corresponding concentration by the total volume of sample.

Using the same method, we estimated the concentration of contaminants elements in the samples. We differentiated between red blood cells (RBCs, easily recognizable because of their refringency and shape) and epididymal cells. We also subjectively assigned three levels of "dirtiness" to each sample, depending on the appearance of the background (A, almost clean; B, many contaminants and some background; C, lots of contaminants and dirty background).

The concentration of epididymal cells and RBCs was also estimated also in the final dilution (after adding extender to reach $100 \times 10^{6}$ spermatozoa $/ \mathrm{mL}$, see below) before freezing.

\subsection{Quality assessment of the collected sperm}

Quality was estimated by assessing motility, membrane functionality and organelle functionality. Only those samples with a proportion of motile sperm higher than $10 \%$ (see below) were analyzed for quality.

Motility assessment was performed using a CASA system. Sperm were diluted $\left(10-20 \times 10^{6}\right.$ cells $\left./ \mathrm{mL}\right)$ in a buffered solution $(20 \mathrm{mmol} / \mathrm{L}$ Hepes, $197 \mathrm{mmol} / \mathrm{L} \mathrm{NaCl}$, $2.5 \mathrm{mmol} / \mathrm{L} \mathrm{KOH}, 10 \mathrm{mmol} / \mathrm{L}$ glucose; $\mathrm{pH} 7,400 \mathrm{mOsm} / \mathrm{kg}$ ), and warmed on a $37{ }^{\circ} \mathrm{C}$ plate for $20 \mathrm{~min}$. Then, a pre-warmed Makler counting chamber (10 $\mu \mathrm{m}$ depth) was loaded with $5 \mu \mathrm{L}$ of sample. The CASA system consisted of an optical phase contrast microscope (Nikon Labophot-2, equipped with negative phase contrast objectives and a warming stage 
at $37^{\circ} \mathrm{C}$ ), a Sony XC-75CE camera, and a PC with the Sperm Class Analyzer software (SCA2002, Microptic, Barcelona, Spain). The magnification was $10 \times$. All samples were analyzed at least twice, in order to discard errors due to incorrect sampling. At least five fields per sample were acquired, making a total of at least 100 motile sperm. Image sequences were saved and analyzed afterwards. CASA acquisition parameters were: 25 images acquired, at an acquisition rate of 25 images per second. For each sperm analyzed, the SCA2002 rendered the following data: VCL (velocity according to the actual path, $\mu \mathrm{m} /$ $\mathrm{s}$ ), VSL (velocity according to the straight path, $\mu \mathrm{m} / \mathrm{s}$ ), VAP (velocity according to the average - smoothed - path, $\mu \mathrm{m} / \mathrm{s}$ ), LIN (linearity, \%), STR (straightness, \%), WOB (wobble, \%), ALH (amplitude of the lateral displacement of the sperm head, $\mu \mathrm{m}$ ), and BCF (frequency of the flagellar beat, $\mathrm{Hz}$ ). We also obtained the percentage of motile spermatozoa (TM; VCL $>10 \mu \mathrm{m} / \mathrm{s}$ ) from each sample. Detailed explanation of these descriptors of sperm movement is provided elsewhere [31-34].

Organelle functionality was evaluated using three different assays, using fluorescent probes and flow cytometry. For each assay, we diluted each sample 1:100 in the hepes buffered solution described for the motility analysis. For viability (plasma membrane intactness), we used the live/dead kit (Molecular Probes, The Netherlands), consisting of propidium ioide (PI; red fluorescence; $1.2 \mu \mathrm{mol} / \mathrm{L}$ ) and SYBR-14 (green fluorescence; $0.1 \mu \mathrm{mol} / \mathrm{L}$ ). We determined the percentage of non-viable (red), viable (green) and moribund (green and red) spermatozoa [35]. For mitochondrial status, we used the JC-1 mitochondrial probe $(1.4 \mu \mathrm{mol} / \mathrm{L})$, which stains mitochondria orange, if they are active (high membrane potential), or green, if they are not active [36]. For acrosomal status, we utilized PNA-FITC (peanut agglutinin, FITC conjugated; $1 \mathrm{mg} / \mathrm{L}$ ), which stains the acrosome green if it is damaged or reacted, and PI $(37 \mathrm{nmol} / \mathrm{L})$. Thus, we obtained four different subpopulations: red (non-viable sperm, intact acrosome), green (viable sperm, damaged acrosome), red and green (non-viable sperm, damaged acrosome), or non-stained (viable sperm, intact acrosome) [37]. Samples were read with the flow cytometer after $30 \mathrm{~min}$ at $37{ }^{\circ} \mathrm{C}$ (live/dead kit and JC-1) or $10 \mathrm{~min}$ at ambient temperature (PI/PNA-FITC). The samples were read using a FACScalibur flow cytometer (Becton Dickinson, CA). For further analysis, we used the percentage of moribund sperm (MOR; live/dead staining), the percentage of viable sperm (VIAB; live/dead staining), the percentage of non-viable sperm with damaged acrosomes (ARNV; PI/PNA-FITC staining), the percentage of viable sperm with damaged acrosomes (ARV; PI/PNA-FITC staining) and the percentage of sperm with active mitochondria (MIT; JC-1 staining).

\subsection{Cryopreservation of the spermatozoa}

The samples (sperm diluted with extender, see above) were kept for $2 \mathrm{~h}$ at $5{ }^{\circ} \mathrm{C}$. Then they were further diluted down to $100 \times 10^{6}$ spermatozoa $/ \mathrm{mL}$, using the same extender, and packaged in $0.25 \mathrm{~mL}$ French straws. Freezing was carried out using a programmable biofreezer (Planner MRII ${ }^{\circledR}$ ), at $-20{ }^{\circ} \mathrm{C} / \mathrm{min}$ down to $-100{ }^{\circ} \mathrm{C}$, and then transferred to liquid nitrogen containers. Thawing was performed by dropping the straws in water at $65{ }^{\circ} \mathrm{C}$ for $6 \mathrm{~s}$. Thawed samples were analyzed for quality as previously described, and we determined the recovery of each parameter by means of subtracting its post-thawed value from its pre-freezing one. 
194

\subsection{Statistical analyses}

Statistical analyses were carried out using the SAS ${ }^{\mathrm{TM}}$ package v8 (SAS Institute, Cary, NC), and $P<0.05$ was used in all tests for statistical significance. For production, contamination and fluorescence data, in order to determine if there were differences between the cuts and flushing method, results obtained for each method were subtracted, and the Wilcoxon signed rank test was used to test $H_{0}=0$. Level of "dirtiness" was analyzed using the $\chi^{2}$-test, or the Fisher's exact test when assumptions for the latter were violated. CASA motility data were analyzed using the general linear models procedure, analyzing the differences between methods of extraction within treatment (initial, prefreezing and post-thawing) and between treatments within method of extraction, including male as a factor in both cases. Classes were compared using adjusted least-squares means. Previously, variables were transformed for normality (log transformation, except for proportions, where arc sine transformation was used).

We also studied the subpopulations defined from the clustering analysis of CASA motility data. The clustering analysis we followed has been presented more extensively in another study [26], thus we will summarize it here $\left(\mathrm{SAS}^{\mathrm{TM}}\right.$ procedure names are given just for reproducibility, since documentation and equivalences to other statistical packages are available elsewhere). Firstly, we reduced the number of descriptors to two principal components (principal component analysis using the Princom procedure), which were used to carry out a non-hierarchical cluster analysis (k-means model, Fastclus procedure). We obtained 15 clusters, which were passed to the Cluster and Tree procedures, in order to perform a hierarchical clustering on them (average linkage method, UPGMA). The final number of clusters was estimated according to the pseudo $t^{2}$, the pseudo $F$ and the cubic clustering criterion (CCC) statistics, produced in each step of the hierarchical clustering (good numbers of clusters are indicated by local peaks of the CCC and pseudo $F$ statistics combined with a small value of pseudo $t^{2}$ and a larger pseudo $t^{2}$ for the next cluster fusion). Clusters were compared between methods of extraction within treatment (initial, prefreezing and post-thawing) and between treatments within method of extraction, using their motility descriptors as comparison variables and taking into account the males (male nested within the corresponding factor). We used the general linear models procedure and, when the model was significant, the respective classes were compared using adjusted leastsquares means. Previously, variables were transformed for normality (log transformation, except for proportions, where arc sine transformation was used). Comparisons of cluster proportions (relative to motile spermatozoa or to the total number - motile + immotile - of spermatozoa) between extraction methods or treatments were carried out by means of the $\chi^{2}$-test.

\section{Results}

\subsection{Sperm production and evaluation of contamination}

The number of spermatozoa obtained was not significantly different using either the cuts or the flushing method. We obtained medians of 493.7 and $648.7 \times 10^{6}$ spermatozoa for 

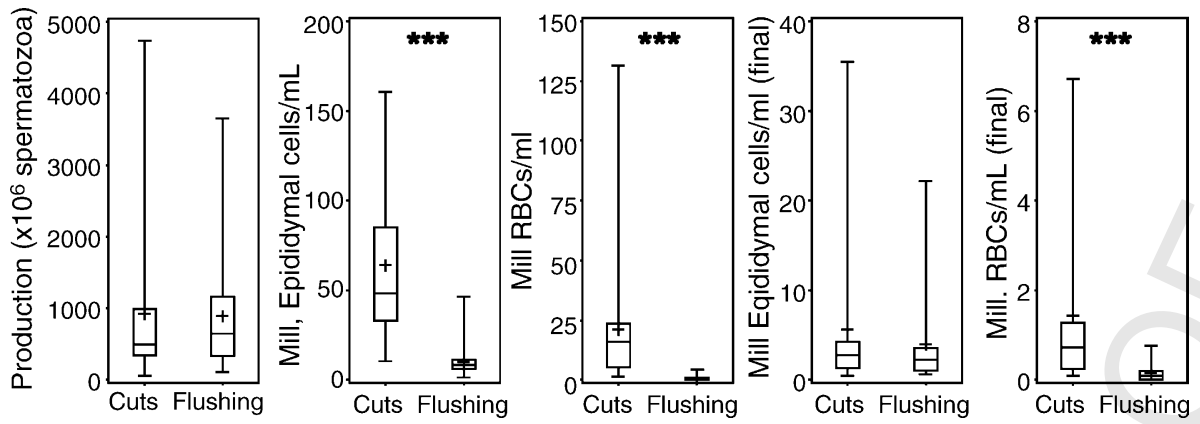

Fig. 1. Production and contamination results for the cuts method and the flushing method. For contamination, results for epidydimal cells and RBCs are shown, considering its concentration in the sample just after extraction (initial) and just before freezing, after diluting it down to $100 \times 10^{6}$ spermatozoa/mL (final). Significances (Wilcoxon signed rank test) are indicated as: ${ }^{+} P<0.1 ;{ }^{*} P<0.05 ;{ }^{* *} P<0.01 ;{ }^{* * *} P<0.001$. In the box plots, the box comprises from the 1 st to the 3 rd quartile, the whiskers indicate the most extreme values, and the horizontal line indicates the median. The cross indicates the mean.

the cuts method and flushing method, respectively (Fig. 1), with very wide interquartile ranges (more than $600 \times 10^{6}$ in both methods). In our study we did not find statistical differences between the two methods.

We found epididymal cells in all the samples, but 34\% (10 of 29) of the samples obtained by flushing were completely free from RBCs. Fig. 1 shows the distribution of the samples for the four contaminant evaluations and the two extraction methods. The samples obtained by means of cuts were much more contaminated than those obtained by means of flushing. After diluting the samples to a final concentration of $100 \times 10^{6}$ spermatozoa/mL before freezing, the concentration of epididymal cells was not significantly different between methods, but the concentration of RBCs was still higher in the case of the cuts method. Considering the "dirtiness" classification, $75.9 \%$ of the samples obtained by flushing had an A score (almost clean), and only a 3.4\% of the samples had a C score. However, in the case of cuts, not only were there as many A samples as B samples (43.3 and $40 \%$, respectively), but also a considerable proportion of $\mathrm{C}$ samples (16.7\%). Differences between both distributions were significant.

\subsection{Sperm quality}

Samples from eight animals were rejected because of poor motility after extraction (TM $<10 \%$; samples of more than $24 \mathrm{~h}$ post-mortem). The results of analyzed samples are shown in Table 1 and Fig. 2. Average motility results (Table 1) did not differ significantly between the two extraction methods when analyzed just after extraction. However, in the pre-freezing and post-thawing analysis, flushed samples had better motility than those obtained by cuts, showing that flushed samples not only had a higher proportion of motile sperm, but also better condition (especially considering VAP and LIN values).

Fluorescence-based analysis showed few differences between extraction methods (Fig. 2). Before freezing, samples obtained by means of cuts had a significantly higher 
Table 1

Values of some motility descriptors depending on extraction method and treatment. Data are expressed as mean \pm S.E.M.

\begin{tabular}{|c|c|c|c|c|c|c|}
\hline Treatment & Extraction & TM $(\%)$ & $\operatorname{VAP}(\mu \mathrm{m} / \mathrm{s})$ & LIN (\%) & $\mathrm{ALH}(\mu \mathrm{m})$ & $\mathrm{BCF}(\mathrm{Hz})$ \\
\hline \multirow[t]{2}{*}{ Initial } & Cuts & $51.38 \pm 5.61 \mathrm{~A}$ & $38.08 \pm 7.27 \mathrm{~A}$ & $48.17 \pm 4.31 \mathrm{AB}$ & $2.02 \pm 0.24 \mathrm{~A}$ & $5.95 \pm 0.55 \mathrm{~A}$ \\
\hline & Flushing & $49.17 \pm 5.94 \mathrm{~A}$ & $46.21 \pm 6.40 \mathrm{~A}$ & $50.99 \pm 3.54 \mathrm{~A}$ & $2.30 \pm 0.21 \mathrm{~A}$ & $6.71 \pm 0.46 \mathrm{~A}$ \\
\hline \multirow[t]{2}{*}{ Pre-freezing } & Cuts & $72.49 \pm 5.98 \mathrm{aB}$ & $50.98 \pm 6.11 \mathrm{aB}$ & $42.11 \pm 2.47 \mathrm{aA}$ & $3.14 \pm 0.32 \mathrm{~B}$ & $7.20 \pm 0.40 \mathrm{~B}$ \\
\hline & Flushing & $84.48 \pm 6.23 \mathrm{bB}$ & $67.63 \pm 7.24 \mathrm{bB}$ & $50.73 \pm 3.94 \mathrm{bA}$ & $3.39 \pm 0.35 \mathrm{~A}$ & $7.25 \pm 0.55 \mathrm{AB}$ \\
\hline \multirow[t]{2}{*}{ Post-thawed } & Cuts & $69.61 \pm 4.30 \mathrm{aB}$ & $60.79 \pm 8.21 \mathrm{~B}$ & $52.58 \pm 5.18 \mathrm{aB}$ & $2.46 \pm 0.18 \mathrm{~B}$ & $7.19 \pm 0.44 \mathrm{aB}$ \\
\hline & Flushing & $80.20 \pm 4.25 \mathrm{bB}$ & $69.68 \pm 8.30 \mathrm{~B}$ & $59.00 \pm 5.01 \mathrm{bB}$ & $2.47 \pm 0.22 \mathrm{~B}$ & $7.76 \pm 0.43 \mathrm{bB}$ \\
\hline
\end{tabular}

a, b: rows (extraction method within treatment) with different letters differ $P<0.05$. A, B, C: rows (treatments within extraction method) with different letters differ $P<0.05$.

\section{Pre-freezing}
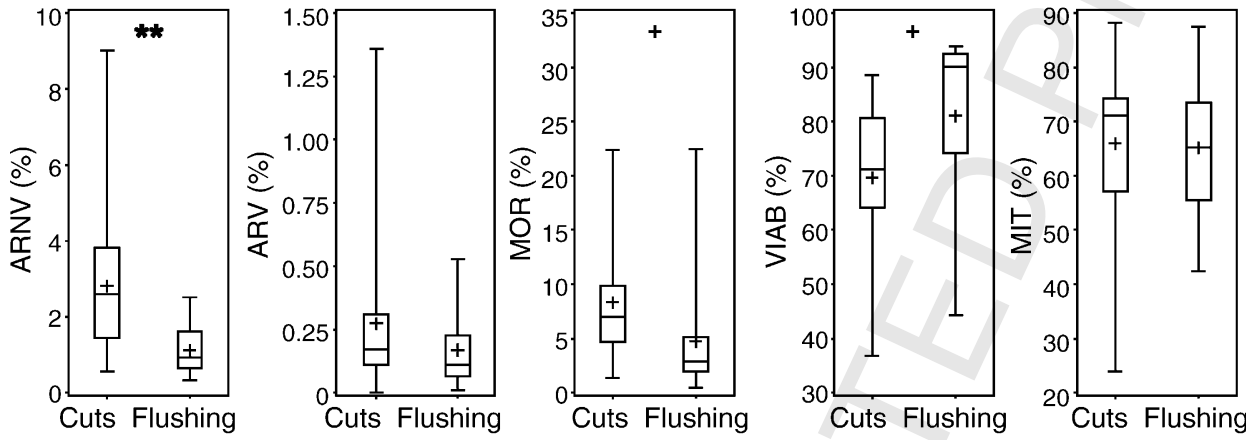

\section{Post-thawing}
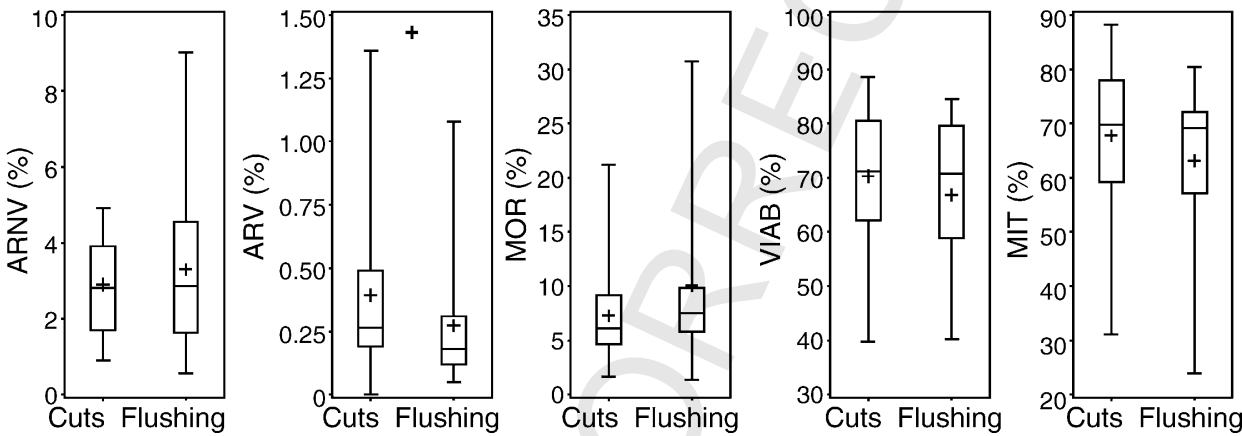

Fig. 2. Comparison of the results obtained analyzing the samples with fluorescent probes and flow cytometry, for the two methods of extraction (pre-freezing, top; and post-thawing, bottom analysis). ARNV: \% acrosome reacted, non-viable spermatozoa; ARV: \% acrosome-reacted, viable spermatozoa; MOR: \% moribund spermatozoa; VIAB: \% viable spermatozoa; MIT: \% spermatozoa with active mitochondria. Significances (Wilcoxon signed rank test) are indicated as: ${ }^{+} P<0.1 ;{ }^{*} P<0.05 ;{ }^{* *} P<0.01 ;{ }^{* * *} P<0.001$. In the box plots, the box comprises from the 1 st to the 3 rd quartile, the whiskers indicate the most extreme values, and the horizontal line indicates the median. The cross indicates the mean. 
proportion of ARNV sperm (non-viable sperm with damaged acrosomes). Nevertheless, we detected a trend towards signification $(P<0.1)$ in the pre-freezing analysis of MOR and VIAB (fewer moribund and more viable sperm for flushing), and in the post-thawing analysis of ARV (more viable sperm with damaged acrosomes sperm for cuts).

\subsection{Sperm subpopulations}

Clustering analysis rendered four different clusters, named CL1, CL2, CL3 and CL4. The characteristics and proportions of these clusters for each extraction method and treatment (initial, pre-freezing and post-thawing) are shown in Table 2. CL1 was composed of slow, non-linear and little active sperm. CL2 spermatozoa were rapid and very linear, with high BCF. CL3 consisted of very fast but not very linear sperm. CL4 consisted of fast and non-linear sperm.

The characteristics of the clusters were affected by treatment and method of extraction, but were very similar in most cases. However, the proportions of the clusters varied greatly (Fig. 3). Samples obtained by means of cuts had a higher proportion of CL2 (42.22\%), followed by CL1 (34.08\%) and CL3 (23.70\%) in the initial analysis, but in the pre-freezing analysis, CL1 increased to more than 50\%, with a similar decrease in CL2. However, in the post-thawing analysis, the proportions of the subpopulations returned to values similar to the initial ones, but with a higher CL1 proportion and lower CL3. We found CL4 only in the post-thawing treatment, and in a very low proportion.

On the other hand, samples obtained by flushing had a very different subpopulation pattern and evolution. Initially, CL2 was clearly the pre-dominant subpopulation, accounting for almost $2 / 3$ of motile sperm, and with CL3 below $10 \%$. Before freezing, the pattern changed radically, since CL3 rose to almost $45 \%$, whereas CL2 fell to below $20 \%$, but CL1 decreased slightly. Remarkably, we found CL4 in the pre-freezing treatment, and with an appreciable proportion. In the post-thawing analysis, the subpopulation pattern changed radically again, with a low proportion of CL1 (11\%), CL2 increasing to more than $50 \%$ and CL3 dropping below 30\%. CL4 decreased to $9 \%$

\section{Discussion}

Although most studies on epididymal sperm describe the method used to salvage the spermatozoa, its evaluation is not considered as one of the objectives. Recently, Cary et al. [24] compared flushing and flotation methods for salvaging sperm from stallion epididymes. The flotation method was preferred because it was easier to prepare and rendered sperm of better quality. However, the two methods did not differ significantly, thus the authors concluded that either method may be acceptable for terminal sperm collection.

In this study, we carried out three different comparisons between cuts and flushing: yield, contamination and quality. Yield - the number of spermatozoa recovered - has a practical direct consequence on the number of doses produced from each post-mortem sample. The significance of this in germplasm banking is evident, especially considering that there is only one opportunity to obtain sperm doses from each male, and that this kind 
Table 2

Values of some motility descriptors depending on extraction method and treatment, by cluster

\begin{tabular}{|c|c|c|c|c|c|c|c|c|}
\hline Cluster & $\operatorname{Tr}^{\mathrm{a}}$ & E.M. $^{b}$ & $\mathrm{ST}^{\mathrm{c}, \mathrm{d}}$ & $\mathrm{SM}^{\mathrm{e}, \mathrm{d}}$ & $\mathrm{VAP}(\mu \mathrm{m} / \mathrm{s})$ & LIN (\%) & ALH $(\mu \mathrm{m})$ & $\mathrm{BCF}(\mathrm{Hz})$ \\
\hline \multirow[t]{6}{*}{ CL1 } & \multirow[t]{2}{*}{ I } & $\mathrm{C}$ & $21.74 \mathrm{aA}$ & $34.08 \mathrm{aA}$ & $17.77 \pm 0.88 \mathrm{~A}$ & $30.53 \pm 1.02 \mathrm{aA}$ & $1.77 \pm 0.06 \mathrm{~A}$ & $4.80 \pm 0.24 \mathrm{aA}$ \\
\hline & & $\mathrm{F}$ & $17.12 \mathrm{Ba}$ & $26.04 \mathrm{~b}$ & $13.63 \pm 1.34 \mathrm{~A}$ & $27.42 \pm 1.55 \mathrm{bA}$ & $1.49 \pm 0.09 \mathrm{~A}$ & $5.01 \pm 0.37 \mathrm{bA}$ \\
\hline & \multirow[t]{2}{*}{$\mathrm{PF}$} & $\mathrm{C}$ & $42.50 \mathrm{aB}$ & $53.13 \mathrm{aB}$ & $28.12 \pm 0.77 \mathrm{aB}$ & $36.24 \pm 0.80 \mathrm{aB}$ & $2.27 \pm 0.04 \mathrm{aB}$ & $6.88 \pm 0.16 \mathrm{aB}$ \\
\hline & & $\mathrm{F}$ & $17.49 \mathrm{Ba}$ & $19.19 \mathrm{bB}$ & $32.51 \pm 1.01 \mathrm{bB}$ & $31.82 \pm 1.05 \mathrm{bB}$ & $2.49 \pm 0.06 \mathrm{bB}$ & $6.22 \pm 0.21 \mathrm{bB}$ \\
\hline & \multirow[t]{2}{*}{ PT } & $\mathrm{C}$ & $29.27 \mathrm{aC}$ & $39.29 \mathrm{aC}$ & $25.60 \pm 1.11 \mathrm{C}$ & $35.74 \pm 1.04 \mathrm{aB}$ & $2.03 \pm 0.07 \mathrm{aC}$ & $6.28 \pm 0.21 \mathrm{C}$ \\
\hline & & $\mathrm{F}$ & $9.66 \mathrm{Bb}$ & $11.24 \mathrm{bC}$ & $28.64 \pm 2.04 \mathrm{C}$ & $28.77 \pm 1.93 \mathrm{bAB}$ & $2.30 \pm 0.13 \mathrm{bB}$ & $6.79 \pm 0.39 \mathrm{~B}$ \\
\hline \multirow[t]{6}{*}{ CL2 } & \multirow[t]{2}{*}{ I } & $\mathrm{C}$ & $26.92 \mathrm{aA}$ & $42.22 \mathrm{aA}$ & $53.86 \pm 3.73 \mathrm{~A}$ & $77.01 \pm 1.70 \mathrm{aA}$ & $1.81 \pm 0.11 \mathrm{~A}$ & $9.84 \pm 0.47 \mathrm{a}$ \\
\hline & & $\mathrm{F}$ & $43.62 \mathrm{bA}$ & $66.34 \mathrm{bA}$ & $54.06 \pm 2.39 \mathrm{~A}$ & $70.14 \pm 1.08 \mathrm{bA}$ & $2.24 \pm 0.07 \mathrm{~A}$ & $9.47 \pm 0.30 \mathrm{~b}$ \\
\hline & \multirow[t]{2}{*}{$\mathrm{PF}$} & $\mathrm{C}$ & $14.83 \mathrm{aB}$ & $18.54 \mathrm{aB}$ & $87.73 \pm 2.97 \mathrm{aB}$ & $83.07 \pm 0.94 \mathrm{~B}$ & $2.64 \pm 0.10 \mathrm{aB}$ & $10.13 \pm 0.37 \mathrm{a}$ \\
\hline & & $\mathrm{F}$ & $18.20 \mathrm{bB}$ & $19.98 \mathrm{bB}$ & $76.10 \pm 1.93 \mathrm{bB}$ & $83.32 \pm 0.61 \mathrm{~A}$ & $2.04 \pm 0.06 \mathrm{bA}$ & $9.15 \pm 0.24 \mathrm{~b}$ \\
\hline & \multirow[t]{2}{*}{ PT } & $\mathrm{C}$ & $30.02 \mathrm{aC}$ & $40.30 \mathrm{aA}$ & $88.93 \pm 1.93 \mathrm{aB}$ & $87.40 \pm 0.85 \mathrm{aC}$ & $1.98 \pm 0.04 \mathrm{aC}$ & $9.35 \pm 0.26$ \\
\hline & & $\mathrm{F}$ & $44.15 \mathrm{Ba}$ & $51.35 \mathrm{bC}$ & $74.55 \pm 1.69 \mathrm{bB}$ & $82.62 \pm 0.75 \mathrm{bB}$ & $1.81 \pm 0.04 \mathrm{bB}$ & $9.27 \pm 0.23$ \\
\hline \multirow[t]{5}{*}{ CL3 } & \multirow[t]{2}{*}{$\mathrm{I}$} & $\mathrm{C}$ & $15.12 \mathrm{aA}$ & $23.70 \mathrm{aA}$ & $79.57 \pm 4.73 \mathrm{aA}$ & $52.65 \pm 2.94 \mathrm{~A}$ & $4.89 \pm 0.27 \mathrm{aA}$ & $7.18 \pm 0.59$ \\
\hline & & $\mathrm{F}$ & $5.01 \mathrm{bA}$ & $7.62 \mathrm{bA}$ & $135.10 \pm 8.85 \mathrm{bA}$ & $50.14 \pm 5.51 \mathrm{~A}$ & $6.17 \pm 0.51 \mathrm{Ab}$ & $8.71 \pm 1.11$ \\
\hline & $\mathrm{PF}$ & $\mathrm{C}$ & $22.66 \mathrm{aB}$ & $28.33 \mathrm{aB}$ & $94.58 \pm 2.10 \mathrm{aB}$ & $43.02 \pm 1.16 \mathrm{aB}$ & $5.65 \pm 0.12 \mathrm{aB}$ & $7.88 \pm 0.28 \mathrm{a}$ \\
\hline & \multirow[t]{2}{*}{ PT } & $\mathrm{C}$ & $24.35 \mathrm{aC}$ & $17.38 \mathrm{aC}$ & $112.99 \pm 2.25 \mathrm{Ac}$ & $62.74 \pm 1.37 \mathrm{aC}$ & $4.44 \pm 0.09 \mathrm{aA}$ & $8.25 \pm 0.34$ \\
\hline & & $\mathrm{F}$ & $12.95 \mathrm{bC}$ & $28.31 \mathrm{bC}$ & $119.41 \pm 1.64 \mathrm{bA}$ & $75.90 \pm 1.00 \mathrm{bC}$ & $3.50 \pm 0.07 \mathrm{bC}$ & $8.41 \pm 0.25$ \\
\hline \multirow[t]{3}{*}{ CL4 } & $\mathrm{PF}$ & $\mathrm{F}$ & $14.64 \mathrm{~A}$ & $16.06 \mathrm{~A}$ & $87.79 \pm 2.74 \mathrm{~B}$ & $23.24 \pm 1.12 \mathrm{~A}$ & $6.48 \pm 0.18 \mathrm{~B}$ & $6.64 \pm 0.40$ \\
\hline & \multirow[t]{2}{*}{ PT } & $\mathrm{C}$ & $2.25 \mathrm{a}$ & $3.02 \mathrm{a}$ & $105.41 \pm 5.75$ & $20.37 \pm 3.26 \mathrm{a}$ & $6.65 \pm 0.24 \mathrm{a}$ & $6.77 \pm 0.73$ \\
\hline & & $\mathrm{F}$ & $7.83 \mathrm{bB}$ & $9.10 \mathrm{bB}$ & $115.22 \pm 4.22 \mathrm{~B}$ & $33.23 \pm 2.39 \mathrm{bB}$ & $5.73 \pm 0.18 \mathrm{bB}$ & $7.00 \pm 0.53$ \\
\hline
\end{tabular}

Data are expressed as adjusted least-squares means \pm S.E.M. a, b: rows (extraction methods within treatment) with different superscripts differ $P<0.05$. A, B, C: rows (treatments within extraction method) with different superscripts differ $P<0.05$.

${ }^{a}$ Treatment. I: initial; PF: pre-freezing; PT: post-thawing.

${ }^{\mathrm{b}}$ Extraction method. C: cuts; F: flushing.

c Proportion considering all the spermatozoa in the sample (motile and immotile).

${ }^{\mathrm{d}} \chi^{2}$ on raw data.

e Proportion considering only motile spermatozoa in the sample. 


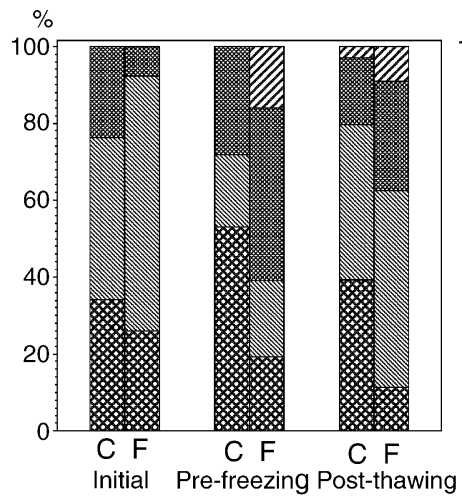

(a) Motile sperm

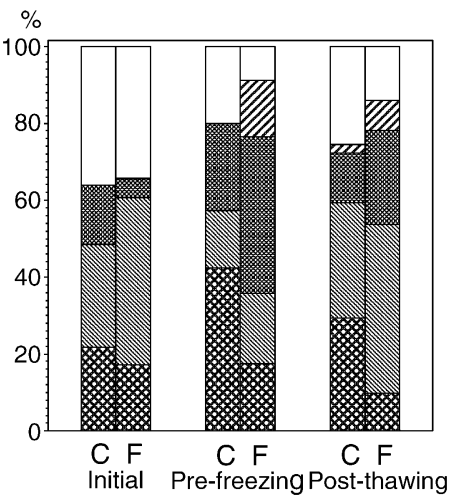

(b) Motile + immotle sperm

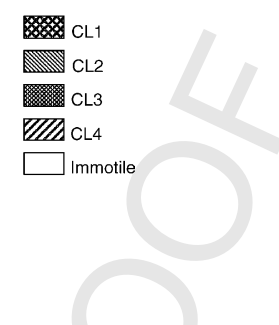
Fig. 3. Representation of the proportions of each cluster (as defined after the clustering analysis of CASA data)
depending on the method of extraction (C: cuts; F: flushing) and treatment (initial, pre-freezing and thawing). Pattern codes for each cluster are given on the right (CL1: slow and non-linear; CL2: rapid and linear; CL3: very rapid and non-linear; CL4: rapid and non-linear). Table 2 shows detailed data and significant differences.

of protocols may be applicable to endangered species or valuable individuals. Although we did not find differences between the two methods, flushing may render better results, because, at least in theory, it would allow us to wipe all the contents of the whole cauda epididymis, including great part of the vas deferens. However, this must be performed carefully, since we have observed that the cuts made for detaching the cauda from the rest of the epididymis, or for helping the sperm to come out, may cut tubules near to the junction between the epididymis and the vas deferens, thus bypassing a great part of the cauda.

However, contamination was more evident using the cuts method. Instead of performing one or two cuts, as in the case of the flushing method, it is necessary to cut the cauda several times in order to ensure that most of the tubules are cut and their contents come out. This, combined with the squeezing and the collection of sperm with the blade, explains the elevated quantity of extraneous elements in the samples obtained by means of cuts. The effect of these particles on the sample is unclear, since most articles related to contamination of sperm samples have dealt with leukocytic or bacterial contamination instead. Nevertheless, Rijsselaere et al. [38] related erithrocyte presence with lower postthawing quality. These authors did not find negative effects of adding blood or serum to extended dog semen, which was cooled and stored for several days, but observed a negative effect if samples treated with whole blood were frozen-thawed. These authors interpreted this as an effect of the hemolysis and free hemoglobin. Furthermore, Verberckmoes et al. [39] found a negative effect of blood and serum in an IVF experiment using bovine semen, which was not noticed when using other methods of analyzing sperm quality.

Therefore, techniques that minimize this kind of contamination would be preferable. Extracting the sperm by means of cuts exposes spermatozoa to the blood and interstitial fluid released when cutting. Although this contact can be minimized by rapidly mixing the sperm with medium or extender, there is a variable interval of time (many seconds at least) in which an appreciable quantity of sperm is exposed to this hazardous environment. Apart 
from the possible effect of RBCs described in the referred studies, blood and interstitial fluid may alter the composition, $\mathrm{pH}$ and osmolality of the spermatic fluid, therefore subjecting the spermatozoa to deleterious conditions. Flushed samples are better protected, not only because the sperm is pushed by extender, but also because the contact with blood and other fluids is limited due to the few cuts performed. This could be also the reason why Cary et al. [24] did not find significant differences between flushing and flotation methods, since in both cases sperm is passed directly from the epididymis to the extender. However, it is possible that contamination could be important in cuts-based methods, potentially impairing impair the fertility of the samples. Furthermore, the effect of contaminants within the genital tract of inseminated females is unknown, considering the use of these samples for AI programmes. Thus, this kind of techniques may be complemented with filtration or purification steps, in order to remove these contaminants.

Flushing also seemed to be better in terms of sperm quality, especially considering motility parameters. It is interesting to note that, for both methods, motility was worse initially (just after recovering the samples) than in pre-freezing or post-thawing, which was already noted in another study [26]. In that study, we considered that it could have been related to the activation of epididymal sperm due to the dilution in the extender $[19,40]$. Alterations in motility characteristics due to dilution could have helped to disclose the differences between methods, due to different responses of sperm recovered by different methods. The effect of sperm dilution in extender (timing, dilution rate, extender composition) must not be disregarded, and deserves further analysis.

Interestingly, although we did not find significant differences considering moribund and viable sperm, viability seemed to be better for flushed samples before freezing, but results were almost equal after thawing. This could be due to the existence of a subpopulation of spermatozoa susceptible to undergoing damage when subjected to environmental changes. Thus, in the samples obtained by means of cuts, this subpopulation may have been affected by extraction, causing the apparently higher proportion of moribund sperm and lower viable sperm. On the other hand, this subpopulation would not have been much affected when using the flushing method, which is possibly less aggressive. However, cryopreservation would have impaired this subpopulation anyway, giving very similar viability results after thawing.

Sperm subpopulation analysis rendered valuable information to support the idea of considerable differences provoked by the extraction method. The analysis indicated that samples obtained by different methods had a different subpopulation pattern. Furthermore, flushed samples may be of better quality, because of the higher proportion of CL2 (rapid and linear sperm), and lower proportion of CL3 (rapid and non-linear sperm), both in the initial and post-thawing analysis. In a previous study on cryopreserved epididymal sperm from red deer, we found that a subpopulation similar to CL2 was possibly related to better post-thawing condition [26]. Moreover, the presence of CL4 in the pre-freezing analysis of flushed samples, and not in samples obtained by means of cuts, suggests that there are more differences, maybe related to the presence of a sensitive subpopulation, as we proposed above. Furthermore, the decrease of CL4 in the post-thawing analysis coincided roughly with the decrease of TM, which may indicate a relationship between CL4 (although not necessarily a coincidence) and that sensitive subpopulation.

In conclusion, flushing would be a more recommendable method for post-mortem salvaging of sperm from the cauda epididymis. Flushed samples were less contaminated 
and had higher quality, and, if done properly, the yield for this method should be similar or even higher than others. Moreover, it can be used in the field without any problem [19]. Although other authors have described similar methods based on injecting only air [2123], injecting some medium seems to be recommendable, because of its protective effect. Also, from our experience, injecting some medium before air eases the extraction of sperm and reduces the risk of breaking the epididymal tubules because of pressure.

On the other hand, flushing may not be as easy to apply in small animals as in big ones, because of the lack of needles of adequate gauge and the low diameter of epididymal tubules, which would made flushing very slow or impossible. Furthermore, cuts were a quicker and easier method, and may be more practical in some cases. Thus, techniques based on cuts cannot be discarded, but it is advisable to carry out an immediate dilution of the sperm with protective diluents, and limiting contamination (especially by blood) as much as possible. Finally, further research in these techniques is necessary to improve this step on the protocols for post-mortem obtaining and cryopreservation of spermatozoa.

\section{Acknowledgements}

This study was supported by the Junta de Castilla y León (AB29). The authors thank Juan Jose Martínez, César Gómez, Juan Carlos Peral, the Territorial Service of Environmental Affairs of León, and the gamekeepers of the hunting reserves of Picos de Europa, Mampodre and Ancares (León, Spain), and Carlos Bernabe (Cáceres, Spain) for their collaboration in the collection of the samples used in this work; and Ana Rocio Diaz, Enrique Anel, Juan Daniel Muro, and Patri Martinez for their help in the processing of the samples.

\section{References}

[1] Holt W, Pickard A. Role of reproductive technologies and genetic resource banks in animal conservation. Rev Reprod 1999;4:143-50.

[2] Turner T. On the epididymis and its role in the development of the fertile ejaculate. J Androl 1995;16:292-8.

[3] Foote R. Fertilizing ability of epididymal sperm from dead animals. J Androl 2000;21:355.

[4] Songsasen N, Tong J, Leibo S. Birth of live mice derived by in vitro fertilization with spermatozoa retrieved up to twenty-four hours after death. J Exp Zool 1998;280:189-96.

[5] An T, Wada S, Edashige K, Sakurai T, Kasai M. Viable spermatozoa can be recovered from refrigerated mice up to 7 days after death. Cryobiology 1999;38:27-34.

[6] Hewitt D, Leahy R, Sheldon I, England G. Cryopreservation of epididymal dog sperm. Anim Reprod Sci 2001;67:101-11.

[7] Yu I, Leibo S. Recovery of motile, membrane-intact spermatozoa from canine epididymides stored for 8 days at $4{ }^{\circ} \mathrm{C}$. Theriogenology 2002;57:1179-90.

[8] Hishinuma M, Suzuki K, Sekine J. Recovery and cryopreservation of sika deer (Cervus nippon) spermatozoa from epididymides stored at $4{ }^{\circ} \mathrm{C}$. Theriogenology 2003;59:813-20.

[9] Hori T, Ichikawa M, Kawakami E, Tsutsui T. Artificial insemination of frozen epididymal sperm in beagle dogs. J Vet Med Sci 2004;66:37-41.

[10] Kaabi M, Paz P, Alvarez M, Anel E, Boixo JC, Rouissi H, et al. Effect of epididymis handling conditions on the quality of ram spermatozoa recovered post-mortem. Theriogenology 2003;60:1249-59. 
[11] Soler AJ, Perez-Guzman MD, Garde JJ. Storage of red deer epididymides for four days at $5{ }^{\circ} \mathrm{C}$ : effects on sperm motility, viability, and morphological integrity. J Exp Zool 2003;295:188-99.

[12] Bartels P, Lubbe K, Kilian I, Friedmann Y, van Dyk G, Mortimer D. In vitro maturation and fertilization of lion (Panthera leo) oocytes using frozen-thawed epididymal spermatozoa recovered by cauda epididymectomy of an immobilized lion. Theriogenology 2000;53:325 (Abstr.).

[13] Kishikawa H, Tateno H, Yanagimachi R. Fertility of mouse spermatozoa retrieved from cadavers and maintained at $4{ }^{\circ} \mathrm{C}$. J Reprod Fertil 1999;116:217-22.

[14] Braun J, Torres-Boggino F, Hochi S, Oguri N. Effect of seminal plasma on motion characteristics of epididymal and ejaculated stallion spermatozoa during storage at $5{ }^{\circ} \mathrm{C}$. Dtsch Tierarztl Wochenschr 1994;101:319-22.

[15] Garde J, Aguado M, Perez S, Garrido D, Perez-Guzman M, Montoro V. Physiological characteristics of epididymal spermatozoa from post-mortem rams. Theriogenology 1994;41:203 (Abstr.).

[16] Garde J, Perez S, Aguado M, Ayllon E, Garrido D, Montoro V. Live birth of hybrid (O. musimon X O. aries) lambs following intrauterine insemination in domestic sheep with mouflon semen obtained $40 \mathrm{~h}$ postmortem. Theriogenology 1995;43:218 (Abstr.).

[17] Garde J, Ortiz N, Garcia A, Gallego L, Landete CT, Lopez A. Post-mortem assessment of sperm characteristics of the red deer during the breeding season. Arch Androl 1998;41:195-202.

[18] Comizzoli P, Mermillod P, Cognie Y, Chai N, Legendre X, Mauge R. Successful in vitro production of embryos in the red deer (Cervus elaphus) and the sika deer (Cervus nippon). Theriogenology 2001;55:649-59.

[19] Gerber D, Irons E, Arlotto A, Cooper D. Quality and freezability of epididymal semen from African buffalo (Syncerus caffer) under field conditions. Theriogenology 2001;55:384 (Abstr.).

[20] Herold FC, Aurich JE, Gerber D. Epididymal sperm from the African buffalo (Syncerus caffer) can be frozen successfully with AndroMed and with Triladyl but the addition of bovine seminal plasma is detrimental. Theriogenology 2004;61:715-24.

[21] Kikuchi K, Nagai T, Kashiwazaki N, Ikeda H, Noguchi J, Shimada A, et al. Cryopreservation and ensuing in vitro fertilization ability of boar spermatozoa from epididymides stored at $4{ }^{\circ} \mathrm{C}$. Theriogenology 1998;50:615-23.

[22] Lambrechts H, van Niekerk F, Coetzer W, Cloete S, van der HG. The effect of cryopreservation on the survivability, viability and motility of epididymal African buffalo (Syncerus caffer) spermatozoa. Theriogenology 1999;52:1241-9.

[23] Ikeda H, Kikuchi K, Noguchi J, Takeda H, Shimada A, Mizokami T, et al. Effect of preincubation of cryopreserved porcine epididymal sperm. Theriogenology 2002;57:1309-18.

[24] Cary JA, Madill S, Farnsworth K, Hayna JT, Duoos L, Fahning ML. A comparison of electroejaculation and epididymal sperm collection techniques in stallions. Can Vet J 2004;45:35-41.

[25] Martinez-Pastor F, Guerra C, Kaabi M, Diaz A, Anel E, Herraez M, et al. Decay of sperm obtained from epididymes of wild ruminants depending on post-mortem time. Theriogenology 2004;63:24-40.

[26] Martinez-Pastor F, Garcia-Macias V, Alvarez M, Herraez P, Anel L, de Paz P. Sperm subpopulations in Iberian red deer epididymal sperm and their changes through the cryopreservation process. Biol Reprod 2004;72:316-27.

[27] Martinez-Pastor F, Guerra C, Kaabi M, Garcia-Macias V, de Paz P, Alvarez M, et al. Season effect on genitalia and epididymal sperm from Iberian red deer, roe deer and Cantabrian chamois. Theriogenology 2004;63:1857-75.

[28] Anel L, Guerra C, Alvarez M, Kaabi M, Anel E, Boixo J, et al. Basic parameters in spermatozoa recovered post-mortem from the Spanish Cantabrian chamois (Rupicapra pyrenaica parva). Theriogenology 2000;53:323 (Abstr.).

[29] Anel L, Guerra C, Alvarez M, Anel E, Martinez A, Rodriguez C, et al. Post-mortem spermatozoa recovery in roe deer (Capreolus capreolus): differences between pre-rutting and rutting season. Theriogenology 2001;55:380 (Abstr.).

[30] Anel L, Guerra C, Alvarez M, Anel E, Martinez A, Boixo J, et al. Effect of post-mortem interval on quality of epididymal spermatozoa in Iberian red deer (Cervus elaphus hispanicus). Theriogenology 2002;57:577 (Abstr.).

[31] Mortimer D, Serres C, Mortimer ST, Jouannet P. Influence of image sampling frequency on the perceived movement characteristics of progressively motile human spermatozoa. Gamete Res 1988;20:313-27. 
[32] Boyers SP, Davis R, Katz D. Automated semen analysis. Curr Probl Obstet Gynecol Fertil 1989;12:172-200.

[33] Davis R, Drobnis E, Overstreet J. Application of multivariate cluster, discriminate function, and stepwise regression analyses to variable selection and predictive modeling of sperm cryosurvival. Fertil Steril 1995;63:1051-7.

[34] Rigau T, Farre M, Ballester J, Mogas T, Pena A, Rodriguez-Gil JE. Effects of glucose and fructose on motility patterns of dog spermatozoa from fresh ejaculates. Theriogenology 2001;56:801-15.

[35] Garner D, Johnson L, Yue S, Roth B, Haugland R. Dual DNA staining assessment of bovine sperm viability using SYBR-14 and propidium iodide. J Androl 1994;15:620-9.

[36] Garner D, Thomas C, Joerg H, Dejarnette J, Marshall C. Fluorometric assessments of mitochondrial function and viability in cryopreserved bovine spermatozoa. Biol Reprod 1997;57:1401-6.

[37] Szasz F, Sirivaidyapong S, Cheng FP, Voorhout WF, Marks A, Colenbrander B, et al. Detection of calcium ionophore induced membrane changes in dog sperm as a simple method to predict the cryopreservability of dog semen. Mol Reprod Dev 2000;55:289-98.

[38] Rijsselaere T, Van Soom A, Maes D, Verberckmoes S, de Kruif A. Effect of blood admixture on in vitro survival of chilled and frozen-thawed canine spermatozoa. Theriogenology 2004;61:1589-602.

[39] Verberckmoes S, van Soom A, de Pauw I, Dewulf J, Rijsselaere T, de Kruif A. Effect of whole blood and serum on bovine sperm quality and in vitro fertilization capacity. Theriogenology 2004;61:25-33.

[40] De Pauw IM, Van Soom A, Maes D, Verberckmoes S, de Kruif A. Effect of sperm coating on the survival and penetrating ability of in vitro stored bovine spermatozoa. Theriogenology 2003;59:1109-22. 